\title{
Formação de Professores em Ambiente Virtual de Aprendizagem: a mineração de dados contribuindo para a análise das interações
}

\section{Teacher's formation in Virtual Learning Environment: data mining contributing to the analysis of interactions}

\begin{abstract}
Resumo:
Este trabalho apresenta parte de uma pesquisa desenvolvida no Programa de Pós-Graduação Multi-institucional e Multidisciplinar em Difusão do Conhecimento. A investigação tem como objetivo analisar os efeitos da utilização de um ambiente virtual de comunicação colaborativa e dialógica para a formação de professores-formadores do curso Mídias na Educação (MEC/UESB). Os pressupostos teóricos que fundamentaram a pesquisa estão baseados na teoria bakhtiniana, em especial no que se refere ao dialogismo. A mineração de dados deu subsídios para a análise das interações, dos acessos, dos diálogos e dos silêncios ocorridos no Espaço Dialógico. As conclusões, ainda que provisórias e parciais, demonstram que os professores ainda resistem a dialogar, construir e difundir conhecimentos em um ambiente virtual de aprendizagem, sob o enfoque da multivocalidade, do favorecimento à expressão da diversidade de sentidos, da polifonia.

Palavras-chave: Formação de professor. Ambiente virtual de aprendizagem. Educação a distância. Mineração de dados.
\end{abstract}

\section{Abstract:}

The objective of this study is to present part of a research developed at the Multi-Disciplinary and Multi-Institutional Post Graduation Program on Knowledge Diffusion. The investigation has as its aim the analysis of the effects of the use of a virtual environment of collaborative and dialogical learning in the formation of teachers of Educational Media (MEC/UESB). The theoretical principles for the research are based on the Bakhtininan theory, regarding dialogism. Data mining offered grounds to analyze the interactions, accesses, dialogs and silences occurred in the Dialogical Space. The conclusions, though transitory and partial, show that the teachers still resist in establishing dialogs and disseminate knowledge in a virtual learning environment under the focus of multivocality, of favoring the expression of the diversity of senses, of polyphony.

Keywords: Teacher formation. Virtual learning environment. Distance learning. Data mining.

SOUZA, Elmara Pereira de; SENA, Claudia Pinto Pereira. Formação de Professores em Ambiente Virtual de Aprendizagem: a mineração de dados contribuindo para a análise das interações. Informática na Educação: teoria \& prática, Porto Alegre, v. 14, n. 2, p. 47-61, jul./dez. 2011.

\section{Elmara Pereira de Souza \\ Universidade Federal da Bahia}

\author{
Claudia Pinto Pereira Sena
}

Universidade Estadual de Feira de Santano

\section{Introdução}

A inserção das tecnologias digitais na escola pode trazer novas possibilidades para o campo do ambiente escolar. Nesse sentido, a formação de professores para a utilização das mídias na educação é fundamental no processo de democratização do acesso. A utilização da Educação a Distância através de ambientes virtuais de aprendizagem (e suas potencialidades) para a formação desses professores é uma boa estratégia.

Há algumas décadas, várias investigações (ALMEIDA, 1996, MORAES, 1999, AXT, 2000, CYSNEIROS, 2003) têm sido feitas para compreender como o uso das tecnologias têm modificado o contexto educacional, o que suscitou muitas discussões acerca da importância da formação dos professores para esse fim. Compreendemos que a formação docente, a pesquisa e a construção do conhecimento são conceitos interligados que operam conjuntamente no contexto mais amplo de formação.

A Secretaria de Educação a Distância do Ministério da Educação (SEED/MEC), em par- 
ceria com várias Universidades Públicas, desenvolveu o curso Mídias na Educação, na modalidade a distância, com o objetivo de proporcionar formação continuada para o uso pedagógico das tecnologias da informação e da comunicação - TV e vídeo, informática, rádio e impresso.

O MEC é o responsável pela concepção, acompanhamento, avaliação e provisão de recursos para o Programa, e as Universidades e Secretarias de Educação participam no desenvolvimento, elaboração, operacionalização, dinamização de momentos presenciais e seleção de participantes. A elaboração e implementação de módulos e percursos, seleção e capacitação de tutores, avaliação e certificação são de responsabilidade das Universidades.

Um dos grandes desafios da universidade é a formação dos professores-formadores ${ }^{1}$ para atuarem nessa modalidade de ensino. Formar uma equipe para trabalhar com educação a distância ( $E a D)$ demanda tempo, estudo, além de recursos financeiros.

Durante dez anos de trabalho na formação de professores para o uso das tecnologias da informação e comunicação (TIC) na educação, observamos que, em vários projetos de formação, há ausência de um espaço de diálogo entre os formadores que favoreça a socialização de suas dúvidas e conquistas, um espaço de formação continuada para os professoresformadores sob o enfoque da multivocalidade, do favorecimento à expressão da diversidade de sentidos, da polifonia.

\footnotetext{
1 No curso Mídias na Educação os professores são chamados de tutores. Nesse trabalho, por questões conceituais, optamos por chamá-los de professores-formadores. Compreendemos que o termo tutor está mais próximo de um modelo de educação a distância mediado pelas tecnologias de massa e designa uma função reativa, ou seja, aquele que apenas tira dúvidas dos alunos. Professor-formador é um termo mais adequado para designar o docente online, aquele que faz a mediação pedagógica no ambiente virtual de aprendizagem, buscando a construção do conhecimento.
}

Essa investigação ${ }^{2}$ parte de uma abordagem qualitativa com ênfase na pesquisa-ação. A principal pergunta que norteou a pesquisa foi: Quais podem ser, na perspectiva de um grupo de professores-formadores de curso a distância, os efeitos da utilização de um ambiente virtual de comunicação colaborativa e dialógica para compartilhamento das atividades desenvolvidas durante o curso, além da possibilidade de construção de novos conhecimentos com o outro, coletiva e colaborativamente (em rede)?

Nesse sentido, foi criado o Espaço Dialógico no ambiente virtual de aprendizagem Moodle com o objetivo de favorecer o diálogo entre os professores-formadores e gestores do curso Mídias na Educação, que é coordenado no Estado da Bahia pela Universidade Estadual do Sudoeste da Bahia (UESB) e, conseqüentemente, contribuir para a formação da equipe.

Durante seis meses de interações neste Espaço Dialógico ${ }^{3}$, observou-se que havia interações e diálogos, porém também muitas resistências. Como a quantidade de dados armazenados era grande, optamos por utilizar as técnicas de mineração de dados para auxiliar na análise dos diálogos e dos silêncios no ambiente virtual. Os dados foram gerados a partir da interação dos professores-formadores e gestores do Curso Mídias na Educação no Espaço Dialógico de outubro de 2009 a março de 2010. Foi utilizada a ferramenta TreeMap (HUMAN COMPUTER INTACTION LAB, 2010) para a mineração visual dos dados.

A ferramenta Treemap é um software de visualização de estruturas hierárquicas, muito efetivo para mostrar atributos de nós, uti-

2 Esta pesquisa tem apoio da Fundação de Amparo a Pesquisa do Estado da Bahia - FAPESB.

3 Essa análise foi feita a partir dos dados referentes a outubro de 2009 a março de 2010. O Espaço Dialógico continua aberto e a pesquisa ainda está sendo desenvolvida. 
lizando tamanhos e cores para diferenciá-los. Dessa maneira, essa ferramenta permite a comparação de nós e sub-árvores, que variam de profundidade na hierarquia da árvore, colaborando na identificação de padrões e exceções (HUMAN COMPUTER INTACTION LAB, 2010).

No relato desta investigação, inicialmente será feita uma contextualização da pesquisa, para, em seguida, abordar as concepções de formação de professor e dialogismo. As seções seguintes tratam do processo de construção do Espaço Dialógico e a mineração dos dados. Finaliza-se, então, com as conclusões e reflexões geradas no processo investigativo.

\section{Contextualizando}

A educação a distância tem crescido muito nos últimos anos. Segundo dados do MEC (BRASIL, 2010), atualmente, a cada 5 alunos de graduação no País, um ingressa em curso a distância. Isso significa que cerca de $20 \%$ de universitários utilizam os recursos da Internet, e, em especial, os ambientes virtuais de aprendizagem para as interações professoraluno, aluno-aluno. Como a legislação do Brasil não permite que os cursos de graduação sejam totalmente a distância, esses alunos também participam de aulas nos pólos presenciais.

Um dos grandes impulsos para o crescimento da $\mathrm{EaD}$ foi a implantação da Universidade Aberta do Brasil (UAB). A UAB é um sistema formado por universidades públicas que oferece cursos a distância em nível de extensão, graduação e pós-graduação para a população brasileira. Uma das prioridades da UAB é a formação de professores que atuam na educação básica do sistema público de ensino. Através do Decreto 5.800 , de 8 de junho de 2006, a UAB foi instituída com o objetivo de expandir e interiorizar a oferta de cursos superiores no Brasil. Na Bahia, a primeira experiência da UAB teve início em 2007, através do curso de Administração da Universidade Estadual da Bahia (UNEB). Esse projeto piloto foi realizado por 27 universidades públicas em parceria com o Banco do Brasil e envolveu cerca de dez mil alunos em todo o Brasil.

Outro projeto desenvolvido pela UAB é o Curso de Especialização Mídias na Educação. Os módulos do curso são elaborados por um consórcio de Instituições Federais de Ensino coordenados por quatro delas: módulo TV e Vídeo - Universidade Federal do Ceará (UFCE), Informática - Universidade Federal do Rio Grande do Sul (UFRGS), Material Impresso - Universidade Federal de Alagoas (UFAL) e Rádio - Universidade Federal de Pernambuco (UFPE). Na Bahia, esse projeto está sendo implementado pela Universidade Estadual do Sudoeste da Bahia (UESB).

O Curso Mídias na Educação tem o objetivo de proporcionar formação continuada para o uso pedagógico das diferentes tecnologias da informação e da comunicação - TV e vídeo, informática, rádio e impressos - de forma integrada ao processo de ensino e aprendizagem, contribuindo para a formação de um leitor crítico e criativo, capaz de produzir e estimular a produção nas diversas mídias. O público-alvo prioritário é o professor da educação básica das escolas públicas brasileiras.

O curso é oferecido a distância nos ambientes e-Proinfo ${ }^{4}$ ou Moodle e é dividido em três ciclos (Figura 1): Ciclo Básico com 120 horas, ciclo intermediário com 60 horas e ciclo

\footnotetext{
40 e-Proinfo é um ambiente virtual colaborativo de aprendizagem desenvolvido pelo MEC que permite a concepção, administração e desenvolvimento de diversos tipos de ações, como cursos a distância, complemento a cursos presenciais, projetos de pesquisa, projetos colaborativos e diversas outras formas de apoio a distância e ao processo ensino-aprendizagem. Na Bahia a UESB utiliza esse ambiente no Curso Mídias na Educação. (BRASIL, 2010)
} 
avançado com 180 horas, num total de 360 horas. O professor-cursista pode optar por cursar apenas o ciclo básico (120h), os ciclos básico e avançado $(120 \mathrm{~h}+60 \mathrm{~h}=180 \mathrm{~h})$ ou os três ciclos (360h) recebendo o título de especialista. Nas duas primeiras opções, o professor recebe o certificado de curso de extensão. A partir das turmas que iniciarem em 2010, o curso terá um formato diferenciado.

\section{Mídias na Educação}

\section{Estrutura do Programa:}

Modular, organizado em ciclos de complexidade crescente:

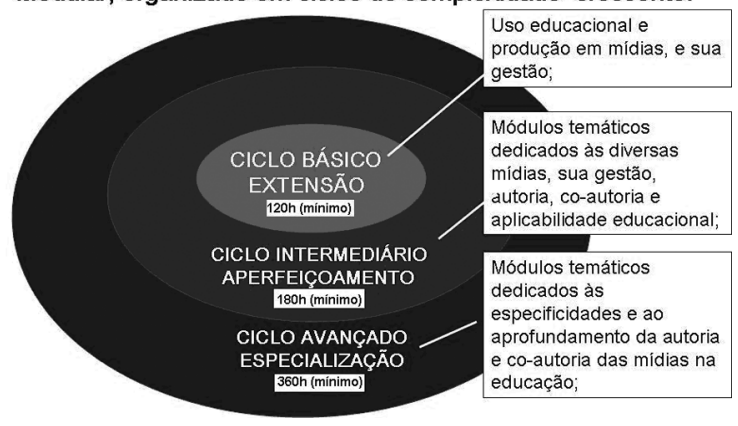

FIGURA 1 - Estrutura Sequencial do Programa Mídias na Educação (turmas iniciadas até 2009) FONTE: MEC, 2010

Apesar do curso ser desenvolvido na modalidade a distância, estão previstos encontros presenciais em cada etapa, com o objetivo de apresentar a proposta do curso e o ambiente virtual de aprendizagem (e-Proinfo), integrar alunos e professores, além de encerrar cada ciclo. Os encontros presenciais, na Bahia, ocorrem na UESB e nos Núcleos de Tecnologia Educacional (NTE).

A comunicação/interação entre alunos e professores durante o curso acontece através do e-Proinfo. Porém, no que se refere à comunicação/interação entre os professoresformadores, observa-se uma subutilização do espaço virtual. Em muitos projetos de formação de professores, percebe-se que a comunicação apresenta apenas uma direção em seu fluxo, ou seja, há uma coordenação que se comunica com os professores-formadores e esses se comunicam com a coordenação, não havendo a comunicação todos-todos (fundamento da interatividade).

Diante dessa constatação, fez-se necessário desenvolver um ambiente virtual de comunicação colaborativa para que os professoresformadores possam dialogar, ampliando seu escopo de compartilhamento.

Para a realização dessa pesquisa, foi criado - Espaço Dialógico para a comunicação colaborativa em rede na formação continuada de professores-formadores do Curso Mídias na Educação.

\section{Formação de Professores}

Quando nos referimos à formação de professores-formadores para o uso das TIC na escola, torna-se fundamental esclarecer qual seja o nosso recorte nesse campo tão amplo de possibilidades. Optamos por uma concepção epistemológica multireferencial que compreende todo conhecimento humano como relativo, parcial e incompleto (FRÓES, 2004). Esse recorte corresponde ao estudo da construção de um espaço dialógico como proposta metodológica de comunicação colaborativa em rede na formação continuada de professores-formadores do Curso Mídias na Educação. Dada a natureza complexa do objeto de estudo, esse recorte permitiu perceber o fenômeno em seu movimento contínuo.

Muitos autores trazem visões diferenciadas sobre o conceito de formação, nesse campo de pesquisa (JOSSO, 2004, KINCHELOE, 1997, MACEDO, 2000, 2006, NÓVOA, 1995, PIMENTA, 1999PIMENTA; ANASTASIOU, 2002, SCHON, 2000). Em nossa investigação, entendemos formação docente como um processo que compreende o sujeito enquanto construtor da sua história, uma formação que 
busca um papel ativo do professor, uma formação fundamentada na experiência de viver a tensão dialética entre teoria e prática (FREI$R E, 1997) ;$ este é um fenômeno que se dá no sujeito na relação com o outro. Portanto, a formação é experiencial e vinculada a valores morais, éticos e políticos.

Sendo, como se sabe, o processo do ensinar indissociável do processo de aprender, consideramos que a formação do professor deve ser pautada na busca da construção do conhecimento, da aprendizagem contínua, da criatividade, da autoria colaborativa, a partir dos desafios apresentados no seu dia-a-dia, no contato com o seu objeto de trabalho, nas reflexões sobre sua experiência.

Observa-se na literatura sobre formação de professores, em muitas pesquisas e projetos de formação, a presença de concepções empíricas, as quais sugerem que o saber fazer possa ser suficiente para a configuração de processos formativos. Porém,

[...] o resultado da formação não se produz na forma de uma finalidade técnica, mas nasce do processo interno de constituição e de formação e, por isso, permanece em constante evolução e aperfeiçoamento [...] Nesse sentido, tudo que ela assimila, nela desabrocha. Mas na formação, aquilo que foi assimilado não é como um meio que perdeu sua função. Antes, nada desaparece na formação adquirida, mas tudo é preservado. A formação é um conceito genuinamente histórico [...] (GADAMER, 1997, p. 50).

A formação do professor na perspectiva da pesquisa, do imbricamento entre teoria e prática, aponta para a linguagem como instrumento essencial, através do qual o indivíduo constitui-se como um sujeito histórico e cultural. Através dela, vários sentidos são colocados em disputa. Para Bakhtin (2000), o aspecto conflituoso e, portanto, ideológico da linguagem, destaca a importância do processo de compreensão dos significados que se dá dialogicamente, numa trama que pressupõe simultaneamente a reflexão e a refração de múltiplas vozes sociais.

Habermas (1982, p. 26 apud FRANCO, 2008, p. 111) diz que "[...] não há possibilidade de individualização sem socialização, assim como não há socialização possível sem individualização [...]". Nesse sentido, as vozes, as interações, o dito e o não-dito, o encontro com o outro no Espaço Dialógico pode favorecer a formação dos professores e a ressignificação da sua prática, pois, os sujeitos no diálogo se constroem e constroem juntos o texto e seus sentidos.

Deste modo, a partir dos pressupostos teóricos de Mikhail Bakhtin (1979, 2000, 2004), é possível abrir novos horizontes e criar novos caminhos metodológicos, de análise, de estudo, a partir da linguagem e do contexto vivenciado pelos professores-formadores no ambiente virtual de aprendizagem (Espaço Dialógico).

\section{Dialogismo}

As ciências humanas estudam o homem em processo de expressão e criação. Estudar o homem independentemente dos textos, ou seja, da linguagem que cria, significa situálo fora do âmbito das ciências humanas. Para Bakhtin (2000), não é possível compreender o homem, sua vida, seu trabalho, suas lutas, senão por meio de textos signos criados ou por criar.

A linguagem é constitutiva dos próprios sujeitos na medida em que estes interagem com os outros durante as situações de comunicação discursiva, e sua consciência, seu conhecimento do mundo, e em última análise, eles próprios, se completam e se constroem continuamente em suas práticas discursivas e nas dos outros. Ao longo de sua história, en- 
tão, o sujeito se constitui à medida que ouve $e$ se apropria de palavras e de discursos de seus pares (pais, amigos, colegas, professores, etc.) tornando-as, em parte, suas próprias palavras. Nesse sentido, Bakhtinafirma que

[...] não são palavras o que pronunciamos ou escutamos, mas verdades ou mentiras, coisas boas ou más, importantes ou triviais, agradáveis ou desagradáveis. [...] A palavra está sempre carregada de um discurso ideológico ou vivencial. (BAKHTIN, 1979, p. 95)

O autor compartilha do princípio de que o homem transforma o mundo através da utilização de instrumentos e é transformado por ele, como uma via de mão dupla. Ele atribui à linguagem o papel de instrumento essencial para esta atuação transformadora e a função de ferramenta psicológica de organização e constituição dos sujeitos. O autor salienta também a organização do discurso como fator determinante nas relações entre os indivíduos engajados em qualquer tipo de interação.

$\mathrm{Na}$ cultura ideológica dos tempos modernos, o monologismo ${ }^{5}$ ainda está presente, e o dialogismo se opõe a ele (BARROS, 1999). O dialogismo diz respeito:

[...] às relações que se estabelecem entre o eu e o outro nos processos discursivos instaurados historicamente pelos sujeitos, que, por sua vez, instauram-se e são instaurados por esses discursos. E ai, dialógico e dialético aproximamse, ainda que não possam ser confundidos, uma vez que Bakhtin vai falar do eu que se realiza no nós, inserindo não na síntese, mas no caráter polifônico dessa relação exibida pela linguagem (BRAIT, 2001, p. 79).

5 Monologismo, baseada na teoria bakhtiniana, é o oposto do dialogismo. "Segundo Bakhtin, no monologismo o autor concentra em si mesmo todo o processo de criação, é o único centro irradiador da consciência, das vozes, [...] O modelo monológico não admite a existência da consciência responsiva e isônoma do outro" (BEZERRA, 2005, p. 192).
O dialogismo é concebido como espaço interacional entre o eu e o tu ou entre o eu e o outro. Compreendemos diálogo não só no sentido restrito de conversa face a face, mas também no sentido de uma comunicação mais ampla que conecta os sujeitos aos contextos. Enquanto o diálogo normalmente é definido como troca ou discussão de idéias, harmonia, pensamos também na dimensão do diálogo como território de conflito ou tensão (BAKHTIN, 1979). Desta forma, o diálogo constitui-se como um grande encontro de vozes e entonações diferentes, diálogos entre pessoas, textos, autores, sentimentos, vidas.

No Espaço Dialógico, o encontro com o outro se dá nas interações, mediado pela linguagem. Os enunciados pressupõem uma atitude responsiva e ativa do outro a quem se dirigem. Bakhtin (2004, p. 79) afirma que "[...] nenhuma enunciação verbalizada pode ser atribuída exclusivamente a quem a enunciou: é produto da interação entre falantes e em termos mais amplos, produto de toda uma situação social em que ela surgiu [...]".

O papel do outro no espaço virtual é essencial na constituição do sentido no diálogo, pois, sempre que falamos, escrevemos, o fazemos pensando em quem está do outro lado da corrente dialógica. O outro atravessa, condiciona o discurso do eu. É impossível uma formação humana sem alteridade, em que o outro não faça parte do meu espaço no mundo, constituindo-me ideologicamente e dandome acabamento.

Compreendendo que no ambiente virtual de aprendizagem os diálogos (na compreensão bakhtiniana) podem favorecer a formação dos professores-formadores é que nos propomos a analisar os ditos e os não-ditos no Espaço Dialógico como forma de compreender melhor a formação a partir de uma proposta metodológica baseada na polifonia e no diálogo. 


\section{A Construção do Espaço Dialógico}

Em agosto de 2009, foi feita uma reunião com os professores-formadores e coordenadores do Curso Mídias na Educação (ciclo avançado) com o objetivo de expor a proposta de pesquisa e convidá-los a participar do Espaço Dialógico. O grupo mostrou-se aberto, aceitando a proposta. Em seguida, foi realizada uma oficina sobre o ambiente Moodle para que todos pudessem conhecer a plataforma como usuários e, especialmente, como editores, pois, a proposta era que todos pudessem criar, formatar, explorar o ambiente virtual de aprendizagem a partir das suas próprias necessidades. O curso Mídias na Educação acontece no e-Proinfo, porém, optamos por construir coletivamente o espaço de interação para os professores-formadores no Moodle por ser esse um ambiente simples e fácil de manusear e, especialmente, rico de possibilidades e potencialidades pedagógicas, proporcionando aos professores a criação de espaços de interação e de diálogo.

$\mathrm{Na}$ oficina acerca do ambiente Moodle, discutiu-se com o grupo como gostariam que se constituísse o Espaço Dialógico. Os professores afirmaram que esse espaço deveria ser como a nossa casa, onde se sentissem a vontade para conversar, para discutir, para aprender e ensinar. O Espaço Dialógico foi sendo construído a partir da metáfora da casa (ver Figuras 2 e 3). Nos primeiros três meses de interação, observou-se que os professores acessaram pouco o ambiente e, apesar de terem sido criados alguns espaços de discussão, poucos se predispuseram ao diálogo. Resolvemos, então, convidar os professoresformadores do ciclo básico para participar do Espaço Dialógico. Em dezembro de 2009, foi enviado um e-mail ${ }^{6}$ para cerca de setenta professores-formadores convidando-os a participar da pesquisa. Cinqüenta e um aceitaram o convite e se inseriram no ambiente. A rede de interação se ampliou, as vozes começaram a aparecer e o ambiente tornou-se mais movimentado e vivo.

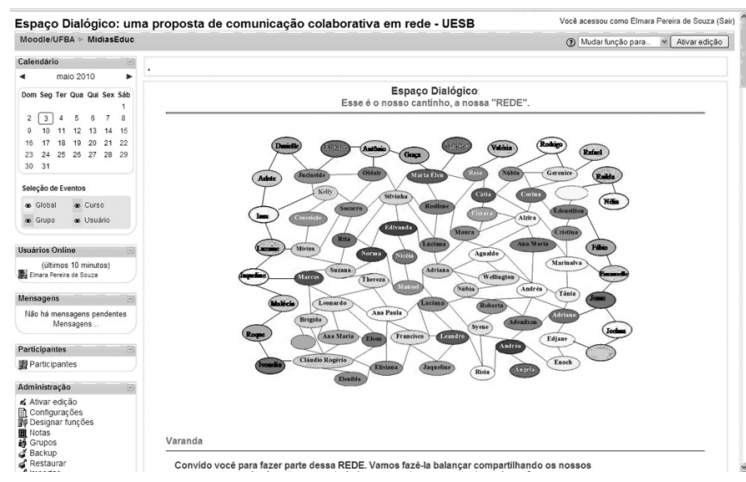

FIGURA 2 - Espaço Dialógico (ambiente Moodle) em Fevereiro de 2010

FONTE: Elaborada pelas autoras, 2010

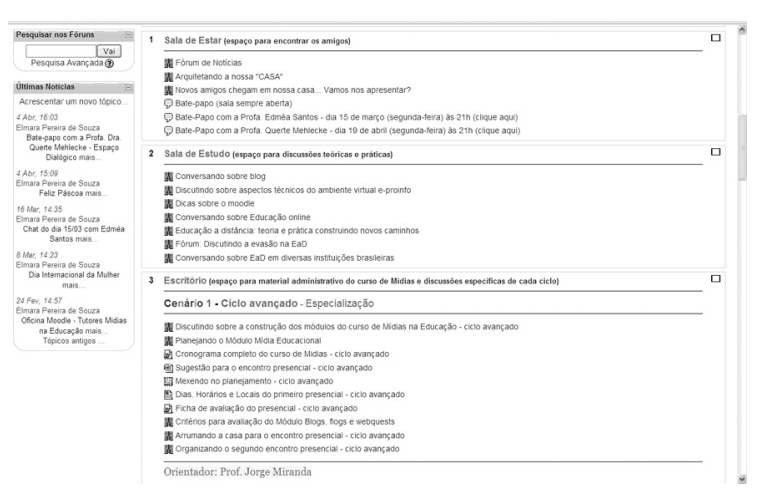

FIGURA 3 - Espaço Dialógico (ambiente Moodle) - espaços de discussão criados pelos professores-formadores do Curso Mídias na Educação

FONTE; Elaborada pelas autoras, 2010

60 convite foi enviado por e-mail porque os professorestutores do ciclo básico estão espalhados por várias cidades da Bahia, dificultando uma reunião presencial para expor a proposta, como foi feito com os professores do ciclo avançado. 
Os professores foram criando fóruns de discussão, wikis, disponibilizando material a partir das necessidades apresentadas na sua prática de Educação a Distância (ex. evasão e avaliação na EaD, atividades do curso Mídias na Educação) além de espaços de formação que ultrapassam a formação profissional (Figuras 4 e 5)

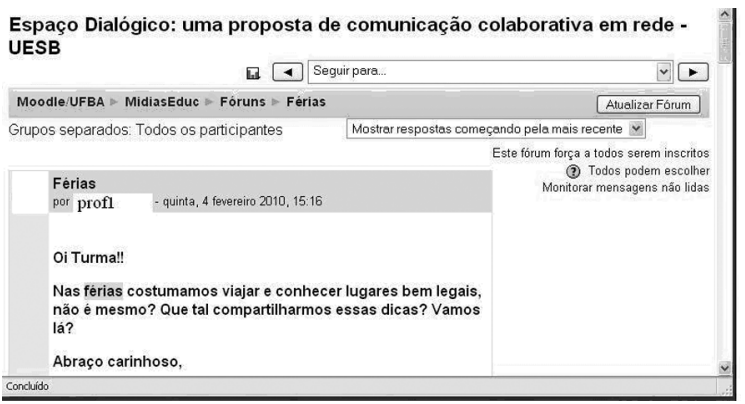

FIGURA 4 - Espaço Dialógico (ambiente Moodle) - fórum para compartilhar dicas de locais interessantes para conhecer

FONTE: Elaborada pelas autoras, 2010

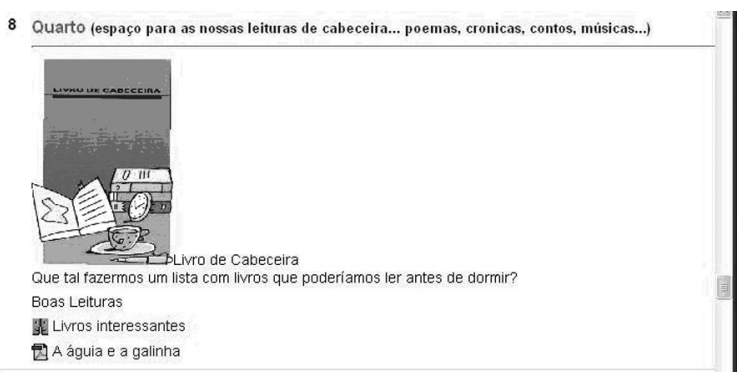

FIGURA 5 - Espaço Dialógico (ambiente Moodle) - tópico para compartilhar dicas de livros

FONTE: Elaborada pelas autoras, 2010

Com cerca de setenta participantes inseridos no Espaço Dialógico, o número de acessos (dados) cresceu, dificultando um acompanhamento individualizado e a análise das interações, dos diálogos e dos silêncios. Como o objetivo da pesquisa é compreender os efeitos da utilização do ambiente virtual na comunicação colaborativa e dialógica para a formação de professores-formadores do curso a distância Mídias na Educação, foi necessário lançar mão das técnicas da mineração de dados para facilitar a organização e visualização desses dados e tentar compreender como os professores estavam utilizando o Espaço Dialógico.

\section{Mineração de Dados}

Cada vez mais, observa-se um crescimento considerável dos dados armazenados em meios magnéticos. Estes dados são ricos, mas precisam ser manipulados, tratados de forma a tornarem-se informações úteis, com significado relevante para quem os necessita. Diante deste cenário, a mineração de dados tornase uma ferramenta extremamente útil para a exploração da informação contida em repositórios de dados, extraindo conhecimento para ser utilizado na tomada de decisões.

Segundo Mendonça (2005), mineração de dados (Data Mining) é o processo de indução de informação não trivial, previamente desconhecida, e potencialmente útil de repositórios genéricos de dados. Com isso, quer-se dizer que, qualquer conjunto de dados armazenados em computadores (ex. páginas HTML) pode ser usado para se induzir conhecimento. É, também, uma etapa do processo mais amplo de KDD (Knowledge Discovery in Databases). KDD, por sua vez, é o processo de descoberta de padrões novos, válidos, potencialmente úteis e em última análise, compreensíveis, em uma base de dados (JUNIOR; CAVALCANTI, 2005).

A Mineração de dados pode também ser entendida como o processo de descobrir conhecimentos interessantes a partir de grandes conjuntos de dados, os quais podem estar armazenados em bases de dados, data warehouses ou em outros repositórios de dados (BARBETTA, 2005). 
Os principais objetivos da mineração de dados são descobrir relacionamentos entre dados e fornecer subsídios para que possa ser feita uma previsão de tendências futuras baseada no passado. Este processo possui algumas fases (MENDONÇA, 2005) (Figura 6), entre elas:

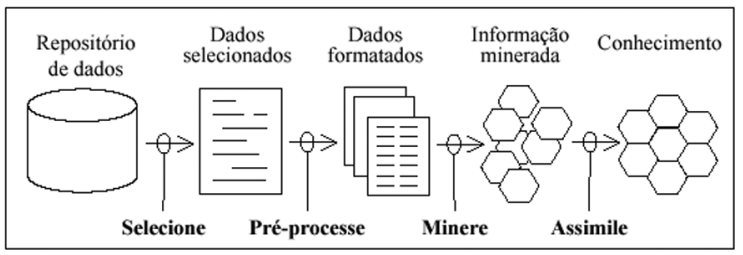

FIGURA 6 - Etapas de um Processo de Mineração FONTE:Mendonça, 2005

a) Definição da problemática;

b) seleção e extração dos dados;

c) pré-processamento dos dados;

d) mineração dos dados;

e) exploração Visual dos dados e resultados;

f) interpretação e assimilação dos dados e extração de conhecimento.

\subsection{Origem, Seleção, Extração e Pré-Processamento dos Dados}

As etapas iniciais da mineração, a origem dos dados (problemática), a seleção e extração dos dados a serem trabalhados e o préprocessamento, juntas, são as etapas que demandam mais tempo, pois é preciso escoIher e ajustar os dados para que a ferramenta usada na mineração possa, adequadamente, ser alimentada e produza os resultados para análise.

Para uma análise, ainda preliminar, dos acessos e, especialmente, dos diálogos no Espaço Dialógico, optou-se por gerar uma única planilha com os logs de acesso de todos os participantes no ambiente Moodle (Figura 7). Entretanto, para que esta planilha fosse utili- zada na ferramenta TreeMap (HUMAN COMPUTER INTACTION LAB, 2010), foi necessário fazer algumas adaptações e tratamento dos dados. Primeiramente, foi incluída uma nova linha, abaixo da linha correspondente aos títulos de cada coluna, correspondente ao tipo de dado manipulado na coluna (i.e. Integer, String, etc.).

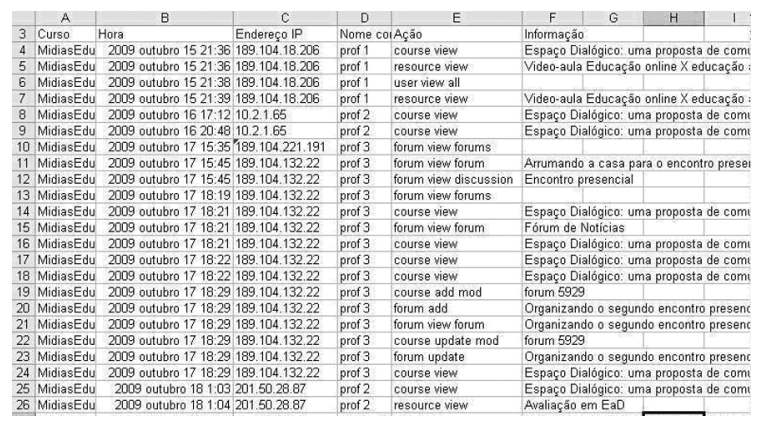

FIGURA 7 - Planilha dos Logs de Todos os Acessos Capturada no Espaço Dialógico (ambiente Moodle) FONTE: Elaborada pelas autoras, 2010

Nesse processo de tratamento dos dados, anterior à mineração, preferiu-se dividir a coluna da data e hora, que trazia toda essa informação em uma mesma coluna (2009 outubro 15 21:36), em três novas colunas, respectivamente Ano, Mês e Dia. Desprezou-se, portanto, o horário de acesso, que não foi considerado relevante para a análise desejada. Outra coluna também eliminada foi a coluna correspondente ao IP da máquina de acesso.

Ainda durante a fase da preparação dos dados (pré-procesamento), foi necessário eliminar os campos vazios, ou atribuindo-lhes valores coerentes, ou eliminando-os do processo de mineração. Optou-se por eliminar as linhas que possuíam campos vazios, pois não era um número significativo em relação ao total.

Após o tratamento desses dados, exportou-se o arquivo para o formato texto (com tabulações). Em seguida, abriu-se o arquivo 
em um editor de texto para salvá-lo com a extensão .tm3, que é a extensão reconhecida pelo TreeMap. A Figura 8, abaixo, ilustra como ficaram os dados após o tratamento descrito acima.

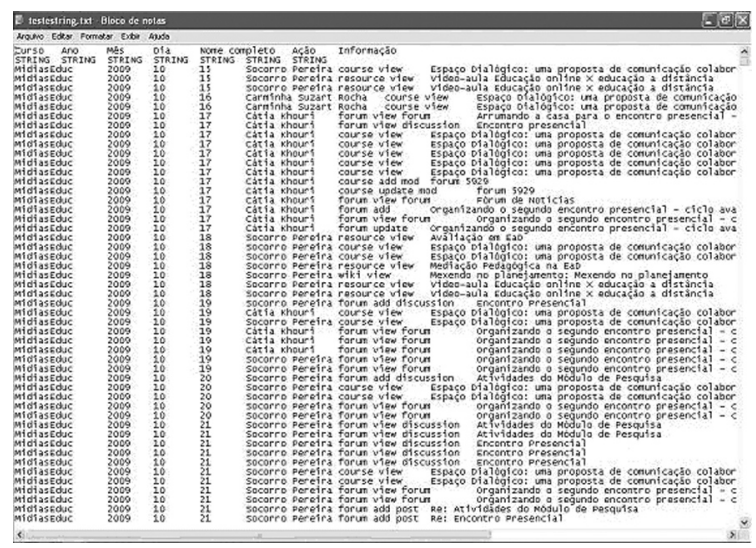

FIGURA 8 - Arquivo Texto Convertido em .tm3, Após PréProcessamento dos Dados

FONTE: Elaborada pelas autoras, 2010

\subsection{Alguns Resultados da Mineração e Extração Visual dos Dados}

Após as etapas iniciais descritas na seção anterior (6.1), é preciso, de posse dos dados tratados, minerá-los, escolhendo a técnica e ferramenta adequadas, para então proceder com a interpretação dos resultados, (Figura $6)$.

A mineração dos dados no TreeMap facilitou a visualização dos acessos, dos caminhos percorridos pelos professores-formadores no Espaço Dialógico. Foram feitos alguns levantamentos que poderão favorecer às futuras análises dos dados. Observou-se que, de outubro a dezembro de 2009, os acessos ao Espaço Dialógico foram poucos. Essa constatação permitiu a tomada de algumas decisões, como, por exemplo, convidar pesquisadores de diversas instituições brasileiras para bate-papos no Espaço Dialógico7. Isso fez com que a dinâmica das interações mudasse e os professores-formadores se interessassem em dialogar no ambiente. As interações em 2010 aumentaram significativamente, conforme mostra a Figura 9.

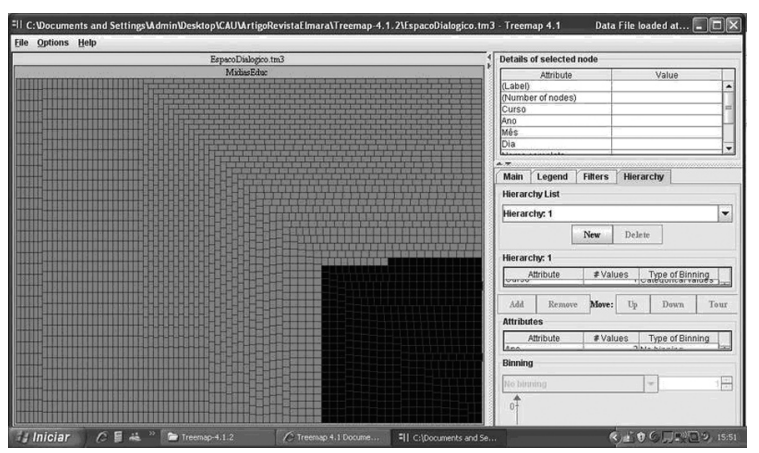

FIGURA 9 - Visualização no TreeMap das Interações no Espaço Dialógico - em preto de outubro a dezembro de 2009 e em cinza as interações de janeiro a março de 2010 FONTE: Elaborada pelas autoras, 2010

Como, nessa pesquisa, utiliza-se a teoria bakhtiniana para discutir as interações no espaço virtual, especificamente, os diálogos ocorridos entre os professores do Curso Mídias na Educação num ambiente criado para a formação a partir da polifonia, do encontro com o outro, compreende-se que os fóruns de discussão são locais privilegiados para as interações. Portanto, visualizar no TreeMap os acessos (ou não) dos professores e os diálogos nos fóruns de discussão é fundamental para as futuras aná-

7 A partir de fevereiro de 2010 foram convidados pesquisadores para bate-papos no Espaço Dialógico com os professores-formadores do Curso Mídias na Educação com o intuído de favorecer a formação desses professores e incentivar o diálogo. Em fevereiro, participou a Profa. Dra Simone Lucena com o tema TV Digital e os desafios para a Educação. Em março, a Profa. Dra Edméa Santos (UERJ) falou sobre a educação a distância e a educação online. Em abril, a Profa. Dra Querte Mehlecke participou de fórum de discussão sobre a experiência da FACCAT na formação de professores para o uso das TIC através de cursos a distância. 
lises qualitativas dessas interações. O fórum é uma interface assíncrona que favorece uma atitude responsiva ativa do outro e é um espaço em que se visualiza a minha ${ }^{8}$ voz atravessada pela palavra do outro, resgatando-se as vozes sociais, as experiências de vida. Desta forma, o diálogo em fórum de discussão constitui-se como um grande encontro de vozes e entonações diferentes, demonstrando que a autoria não é individual, e sim, coletiva.

Com a visualização no TreeMap, observouse que a quantidade de acessos aos fóruns de discussão foram muitos, porém, poucos foram os que contribuíram para as discussões (Figuras 10 e 11). A Figura 10 mostra o acesso por ação e ilustra quais as ações mais solicitadas no ambiente virtual, nos anos de 2009 (cinza mais claro) e 2010 (cinza mais escuro). A hierarquia utilizada foi Curso, Ação e dentro de cada ação, os acessos por ano. A Figura 11 omite as ações de menor acesso. São, no total, 2970 nós (nó representa cada linha do arquivo .tm3 gerado, ou melhor, cada acesso de um participante). Foram escondidos, omitidos 43 nós correspondentes a 19 ações menos acessadas, como ilustra o retângulo sombreado de cinza com borda preta (canto direito) da imagem anterior (Figura 10).

A partir dessas imagens, percebe-se, claramente, que muitos professores acessaram o Espaço Dialógico, porém, as ações fórum view e course wiew foram as mais significativas e demonstram que eles acessaram o ambiente, mas não interagiram. A ação forum add (lado direito da Figura 11), que indica a postagem no fórum, está bem menor indicando que os professores postaram poucas mensagens. Alguns acessam apenas para fazer download de textos ou participar de Chat.

8 Utiliza-se a expressão minha com a intenção de falar da pessoa, de qualquer professor que participa da corrente dialógica no ambiente virtual.

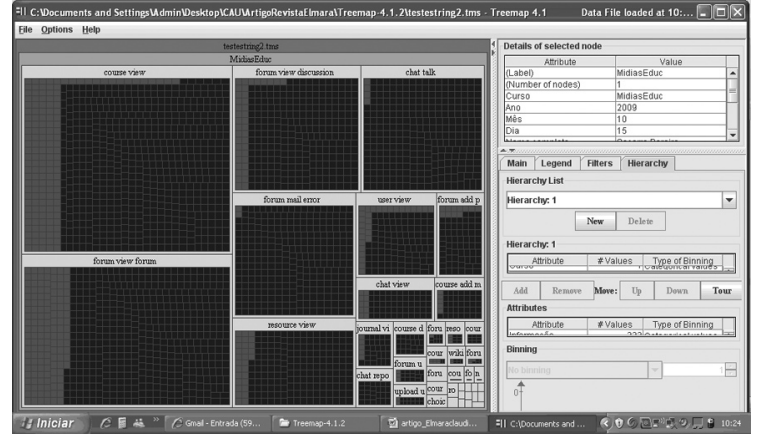

FIGURA 10 - Visualização no TreeMap das Principais Ações no Espaço Dialógico - em azul as interações de 2010 e em rosa de 2009

FONTE: Elaborada pelas autoras, 2010

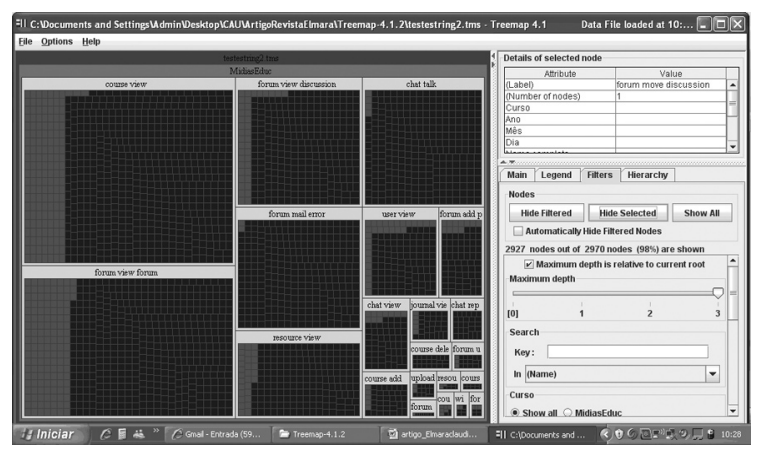

FIGURA 11 - Visualização no TreeMap das Principais Ações no Espaço Dialógico - em azul as interações de 2010 e em rosa de 2009

FONTE: Elaborada pelas autoras, 2010

Foi utilizado também o filtro de busca das ações onde a palavra view aparece (Figura 12), demonstrando mais uma vez que os participantes pouco interagiram entre si e apenas visualizaram as informações, sejam informações do curso, do fórum, do chat ou de outras interfaces do Espaço Dialógico.

Quando utilizado o filtro de busca pela palavra add (Figura 13), que indica que os professores postaram/adicionaram mensagens, percebe-se o menor número de interações em ações que indicam diálogo entre os pares. O retângulo maior em destaque é da ação Forum 


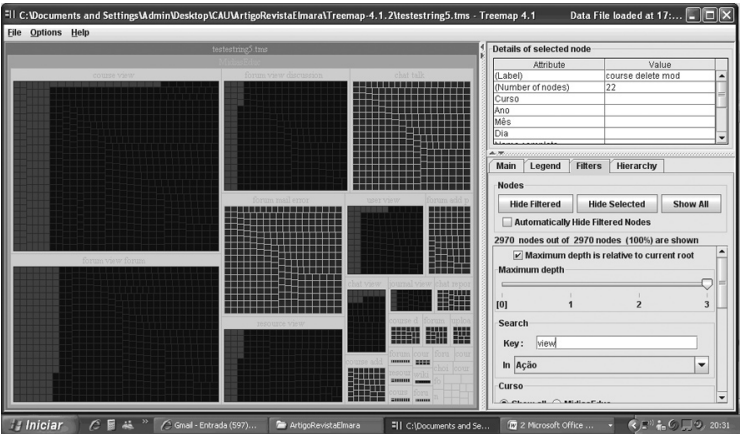

FIGURA 12 - Visualização no TreeMap das Principais Ações no Espaço Dialógico - filtro palavra view FONTE: Elaborada pelas autoras, 2010

add post, correspondendo a 76 nós (acessos). O intermediário é da ação Course add mod (41 acessos) e os menores são respectivamente das ações Forum add, Resource add e Forum add discussion, cada um com 9, 9 e 7 acessos (nós). No total, essas ações perfazem 142 acessos (nós), dos 2970 nós mapeados, correspondendo a aproximadamente $5 \%$ do total de acessos.

Esse percentual de acessos em atividades que equivalem a alguma ação de interatividade é muito pequeno, demonstrando mais uma vez que as vozes permanecem ainda escutando, mais do que falando.

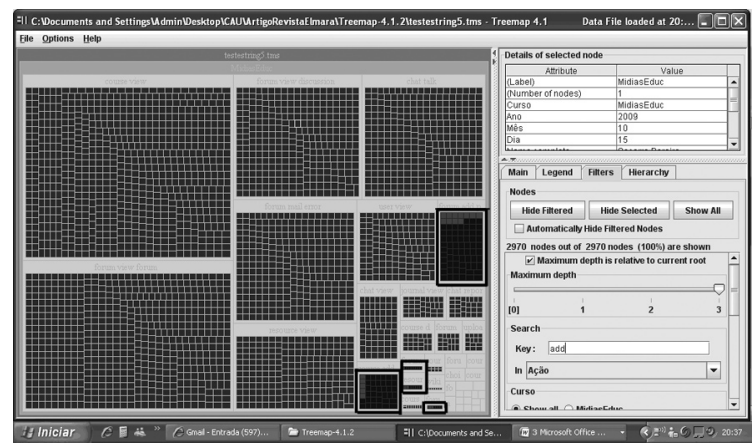

FIGURA 13 - Visualização no TreeMap das Principais Ações no Espaço Dialógico - filtro palavra add FONTE: Elaborada pelas autoras, 2010
A escolha pela mineração visual de dados permitiu, com mais clareza, perceber graficamente as distorções e distanciamentos existentes entre os acessos a ações passivas e ações ativas. A escolha da hierarquia (Curso, Ação) privilegiou essa visualização. Dentro desta hierarquia, filtros foram utilizados (como descritos anteriormente) para melhorar a compreensão da situação por contraste visual (maior ou menor quantidade visualizada).

Durante o trabalho de busca de semelhanças, padrões e/ou diferenças, outras hierarquias foram testadas, como: Curso, Ação e Informação e Curso, Nome Completo do participante. Entretanto, essas duas novas hierarquias não permitiram conclusões diferentes das anteriores. Um terceiro nível a mais na primeira dessas hierarquias (o nível Informação) só aumentou a complexidade visual, não contribuindo efetivamente para definição de outros padrões. A segunda hierarquia (Curso, Nome Completo) é útil para identificar que participantes colaboraram mais ou menos, e em que ações específicas. Como o objetivo desse trabalho não é de identificar os sujeitos, mas sim de tentar identificar quais os movimentos (ativos ou passivos, de escuta ou de fala) foram privilegiados pelo grupo, não foi de interesse utilizar essa hierarquia.

\section{Conclusões}

A realização deste estudo tem proporcionado a reflexão sobre uma metodologia de formação de professores-formadores para atuarem em cursos online a partir da interação dialógica, do apoio do outro, da produção de novos sentidos, do encontro com outros sentidos, sob o enfoque da polifonia.

O Espaço Dialógico criado pelos professores-formadores do Curso Mídias na Educação está fazendo emergir subjetividades e, atra- 
vés do embate dos sentidos, novos sentidos estão sendo produzidos, criando possibilidades de mudança no contexto da formação de professores e de reflexão sobre a atuação em cursos a distância.

A mineração de dados permitiu a visualização dos acessos dos professores-formadores no Espaço Dialógico e favoreceu a tomada de decisões e as mudanças de caminhos durante a pesquisa. Observa-se que é necessário criar estratégias para a construção de espaços de interação dialógica entre os professores, com incentivo a atitude responsiva ativa em que as vozes dos integrantes do grupo possam se fazer ouvir, e os enunciados de um se encontrem com os enunciados do outro, criando outros enunciados, outros sentidos.

A escolha da ferramenta visual (Treemap) para mineração foi um fator que colaborou para a análise dos encontros e desencontros entre os pares, no sentido de definir padrões e exceções nos movimentos dos professores no espaço virtual. Perceber os caminhos percorridos, as falas, os silêncios das pessoas no ambiente virtual permitiu observar, refletir e avaliar, durante o processo da pesquisa, as metamorfoses que aconteceram no Espaço Dialógico favorecendo a tomada de decisão.

A análise dos dados, ainda preliminar e parcial, nos mostra que muitos professores ainda resistem a dialogar, compartilhar, construir e difundir conhecimentos em um ambiente virtual de aprendizagem. Porém, os professores, quando dispostos a participar do espaço virtual e apoiados por um coletivo no contexto dialógico, podem favorecer a sua própria formação, além de auxiliar na formação do outro através da disponibilidade de dialogar na perspectiva de uma mudança de contexto.

\section{Referências}

ALMEIDA, M.E. Informática e Educação: diretrizes para uma formação reflexiva de professores. 1996. Dissertação (Mestrado) - Programa de Pós-Graduação em Educação: Supervisão e Currículo, Pontifícia Universidade Católica de São Paulo, 1996, São Paulo, BR-SP.

AXT, M. Tecnologia na Educação, Tecnologia Para a Educação: um texto em construção. Informática na Educação: teoria \& prática, Porto Alegre, v. 3, n. 1, p. 51-62, set. 2000.

BAKHTIN, M. Marxismo e Filosofia da Linguagem. São Paulo: Hucitec, 1979. . Estética da Criação Verbal. São Paulo: Martinz Fontes, 2000.

O Freudismo. Tradução Paulo Bezerra. São Paulo: Martins Fontes, 2004.

BARBETTA, P.A. Mineração de Dados: Data Mining. Florianópolis: UFSC, 2005. Disponível em: <www.inf.ufsc. br/ barbetta/disciplinas/download/DataMining.ppt> Acesso em: abr. 2005.

BARROS, D.L.P. Dialogismo, Polifonia e Enunciação. In: ; FIORIN, J.L. (Org.). Dialogismo, Polifonia, Intertextualidade em Torno de Bakhtin. São Paulo: EDUSP, 1999. 
BEZERRA, P. Polifonia. In: RAIT, B. (Org.). Bakhtin, Conceitos-Chave. São Paulo. Contexto, 2005.

BRAIT, B. A Natureza Dialógica da Linguagem: formas e graus de representação dessa dimensão constitutiva. In: FARACO, C.A; TEZZA, C.; CASTRO, G. (Org.). Diálogos com Bakhtin. Curitiba: Ed. UFPR, 2001. P. 69 -92 .

BRASIL. Ministério da Educação. Secretaria de Educação a Distância. Educação. [site] Brasília, 2010. Disponível em: <http://portal.mec.gov.br/index.php?option=com content\&view=article\&id=138:eproinfo\&catid=114: sistemas-do-mec $>$ Acesso em: 13 maio 2010.

CYSNEIROS, P.G. Programa Nacional de Informática na Educação: novas tecnologias, velhas estruturas. In: ARRETO, R. G. (Org). Tecnologias Educacionais e Educação a Distância: avaliando políticas e práticas. Rio de janeiro: Quartet, 2003.

FRANCO, M.A.S. Pesquisa-Ação e Prática Docente: articulações possíveis. In: PIMENTA, S.G; FRANCO, M.A. (Org). Pesquisa em Educação: possibilidades investigativas/formativas da pesquisa-ação. São Paulo: Ed. Loyola, 2008. P. 103-138.

FREIRE, P. Professora Sim, Tia Não: cartas a quem ousa ensinar. São Paulo: Loyola, 1997.

FRÓES, T. Impactos das Tecnologias de Informação e Comunicação e na (In)formação do Cidadão-Trabalhador: construindo um quadro teórico-analítico multirreferencial a partir de contribuições da literatura do final do século XX. Revista da FACED, Salvador, n, 8, p. 65-80, 2004.

GADAMER, H.G. Verdade e Método: traços fundamentais de uma hermenêutica filosófica. Petrópolis: Vozes, 1997.

HUMAN COMPUTER INTACTION LAB. Treemap. Disponível em: <http://www.cs.umd.edu/hcil/treemap/demos/> Acesso em abr. 2010.

JoSSO, M.C. Experiências de Vida e Formação. São Paulo: Cortez, 2004.

JUNIOR, A. de F.; CAVALCANTI, A.I.B. Softwares de Mineração de Dados. Disponível em: <http://www.cin. ufpe.br/ compint/aulas-IAS/kdd-022/ SoftwaresMineracaoDados.ppt> Acesso em: abr. 2005.

KINCHELOE, J. A Formação do Professor Como Compromisso Político: mapeando o pós-moderno. Porto Alegre: Artes Médicas, 1997.

MEC. 2010. Curso Mídias na Educação. http://portal.mec.gov.br/index.php?option=com_content\&view=articl e\&id=12333\&Itemid=682 Acesso em 04 de fevereiro de 2011.

MACEDO, R.S. A Etnopesquisa Crítica e Multirreferencial nas Ciências Humanas e na Educação. Salvador: Edufba, 2000. 
MENDONÇA, M. Mineração de Dados. Salvador: Universidade Salvador/NUPERC, 2005. Etnopesquisa Crítica Etnopesquisa-Formação. Brasília: Liber Livro, 2006.

MORAES, M.C. Novas Tecnologias Para o Uso das Tecnologias da Informação na Educação. In: FAZENDA, I. et al. Interdisciplinaridade e Novas Tecnologias. Campo Grande/MS: Ed. UFMG, 1999.

NÓvOA, A. Os Professores e sua Formação. Lisboa: Dom Quixote, 1995.

PIMENTA, S.G. (Org.). Saberes Pedagógicos e Atividade Docente. São Paulo: Cortez, 1999. .; ANASTASIOU, L.G. Docência no Ensino Superior. São Paulo: Cortez, 2002.

SCHON, D.A. Educando o Profissional Reflexivo: um novo design para o ensino e a aprendizagem. Porto Alegre: Artmed, 2000.

Recebido em 20 de maio de 2010.

Aprovado para publicação em 28 de setembro de 2010.

\section{Elmara Pereira de Souza}

Doutoranda no Programa de Pós-graduação muliti-institucional e multidisciplinar em Difusão do Conhecimento. Universidade Federal da Bahia. Salvador/BA - Brasil. E-mail: elmarasouza@yahoo.com.br

\section{Claudia Pinto Pereira Sena}

Professora Assistente do Departamento de Ciências Exatas da Universidade Estadual de Feira de Santana (UEFS). Feira de Santana/BA - Brasil. E-mail: caupinto.sena@gmail.com 